\title{
Ubiquitination Acutely Regulates Presynaptic Neurotransmitter Release in Mammalian Neurons
}

\author{
Gina V. Rinetti ${ }^{1,2,4}$ and Felix E. Schweizer ${ }^{1,2,3,4}$ \\ ${ }^{1}$ Department of Neurobiology, David Geffen School of Medicine at UCLA, ${ }^{2}$ Brain Research Institute, ${ }^{3}$ Molecular Biology Institute, and ${ }^{4}$ Molecular, Cellular, \\ and Integrative Physiology Interdepartmental Graduate Program, University of California, Los Angeles, Los Angeles, California 90095-1763
}

The ubiquitin proteasome system (UPS) plays a crucial role in modulating synaptic physiology both presynaptically and postsynaptically, but the regulatory mechanisms remain obscure. To determine acute effects of proteasome inhibition on neurotransmission, we performed whole-cell voltage-clamp recordings from cultured rodent hippocampal neurons. We find that proteasome inhibitors induce a strikingly fast, severalfold increase in the frequency of both miniature (mini) and spontaneous synaptic currents at excitatory and inhibitory synapses. The lack of change in mini amplitude and kinetics indicates a presynaptic site of action. This effect does not depend on increased levels of presynaptic proteins, previously suggested as proteasomal targets. Furthermore, blockade of the UPS using E1-activating enzyme inhibitors also increases mini frequency, demonstrating that accumulation of ubiquitinated proteins is not required. Overall, these data suggest that the UPS not only orchestrates protein turnover, but also dynamically regulates the activity state of presynaptic proteins, thus crucially shaping synaptic transmission.

\section{Introduction}

Protein degradation has recently been implicated as a modulator of synaptic physiology (Bingol and Schuman, 2004; Yi and Ehlers, 2007; Haas and Broadie, 2008). A major degradation pathway is the ubiquitin-proteasome system (UPS), which controls not only the half-life, but also the activity state, of proteins by covalently tagging them with ubiquitin. Three key enzymatic activities mediate ubiquitination: the E1 ubiquitin-activating enzyme (E1; one or two genes), the E2 ubiquitin-conjugating enzyme (E2; tens of genes) and the E3 ubiquitin-ligase [E3; 500-1000 genes (Kaiser and Fon, 2007)]. The potential for specificity for protein ubiquitination thus rivals that of protein phosphorylation mediated by $\sim 500$ kinases (Manning et al., 2002). Moreover, several synapse-specific E3 ligases have been identified (Shimura et al., 2000; DiAntonio et al., 2001; Yao et al., 2007). These observations raise the question whether ubiquitination could serve a modulatory - in addition to a degradative-role at the synapse.

Substantial evidence supports a prominent postsynaptic role for UPS-dependent protein degradation and for protein synthesis, as comediators of plasticity in mammals (Ehlers, 2003; Bingol and Schuman, 2004; Fonseca et al., 2006; Karpova et al., 2006; Dong et al., 2008). There is less, albeit growing, evidence that

\footnotetext{
Received July 30, 2009; revised Jan. 7, 2010; accepted Jan. 9, 2010.

This work was supported by grants from the National Institutes of Health (DA 026922), the UCLA Udall Parkinson Disease Center of Excellence (NS038367), and the American Parkinson Disease Association. We thank G. David, R. Jones, and T. Tasoff for technical assistance and all members of the Schweizer laboratory for their input. We are grateful to G. M. Besserer, J. M. Bronstein, K. Fehlhaber, C. B. Gundersen, R. Jones, K. C. Martin, T. O'Dell, T. S. Otis, A. Voss, and S. A. White for insightful discussions. G.V.R. conducted and analyzed the experiments. G.V.R. and F.E.S designed the experiments and wrote the manuscript.

Correspondence should be addressed to Felix E. Schweizer, Department of Neurobiology, David Geffen School of Medicine at UCLA, CHS 63-323, 650 Charles E. Young Drive South, Los Angeles, CA 90095-1763. E-mail: felixs@ucla.edu.

DOI:10.1523/JNEUROSCI.3712-09.2010

Copyright $\odot 2010$ the authors $\quad 0270-6474 / 10 / 303157-10 \$ 15.00 / 0$
}

indicates a presynaptic contribution of the UPS to synaptic physiology (Wilson et al., 2002; Willeumier et al., 2006; Yao et al., 2007). For example, the UPS plays a significant role at presynaptic terminals during development by regulating axon growth and growth cone guidance (Lewcock et al., 2007; Fulga and Van Vactor, 2008). In Aplysia, $24 \mathrm{~h}$ inhibition of the proteasome enhances the number of presynaptic boutons and increases the strength of synaptic transmission (Zhao et al., 2003). Inhibition (45 min) of the UPS at the Drosophila neuromuscular junction increases synaptic transmission due to accumulation of the synaptic vesicle regulator Dunc-13 (Speese et al., 2003). In hippocampal neurons, a $2 \mathrm{~h}$ block of the proteasome increases the size of the recycling pool of vesicles in an activity and protein kinase A (PKA)dependent manner (Willeumier et al., 2006). The presynaptic E3-ubiquitin-ligase, scrapper, regulates levels of the vesicle priming protein RIM1, thus modifying neurotransmitter release (Yao et al., 2007). Together, these data support the hypothesis that the UPS regulates presynaptic physiology through distinct pathways in diverse neuronal systems and in different species.

We investigate the effect of UPS blockers on synaptic physiology in cultured neurons. We find that UPS inhibition triggers a very rapid and strong increase in spontaneous neurotransmitter release. The frequency of excitatory and inhibitory miniature postsynaptic currents (minis) increases severalfold within minutes of UPS inhibition with no change in amplitude, suggesting a presynaptic effect. In contrast to previous reports, we find no evidence for the involvement of Munc-13 or Rim1 in this process. The increase is calcium and protein synthesis independent. Blocking the UPS upstream of the proteasome, by inhibiting E1 activity, also leads to a rapid increase in mini frequency. Our results thus suggest the involvement of rapid and dynamic protein ubiquitination in the regulation of synaptic transmission. 


\section{Materials and Methods}

Tissue culture. We used primary hippocampal neurons from CA1-CA3 regions of Sprague Dawley rat pups cultured at postnatal day 0 to 2 as previously described (Sippy et al., 2003) with minor modifications. Hippocampi were dissected in 20\% fetal bovine serum (FBS; Hyclone) in HBSS (Life Technologies). Tissue pieces were digested with $1 \mathrm{mg} / \mathrm{ml}$ papain for $15 \mathrm{~min}$ at $37^{\circ} \mathrm{C}$, followed by mechanical dissociation with Pasteur pipettes. Cells were plated at a density of $30,000-50,000 / \mathrm{cm}^{2}$ on Matrigel (Beckton Dickinson)-coated glass coverslips inside a $15-\mathrm{mm}-$ diameter cloning cylinder. Cells were grown in Minimal Essential Medium (MEM; Life Technologies) supplemented with 0.5\% glucose, $100 \mathrm{mg} / \mathrm{L}$ bovine transferrin (Calbiochem), $24 \mathrm{mg} / \mathrm{L}$ insulin, $2 \mathrm{~mm}$ Glutamax-1 (Invitrogen), and 10\% FBS (Hyclone). After 24-48 h, the culture medium was adjusted to a final concentration of 5\% FBS, 2\% B27 (Invitrogen), and $8 \mu \mathrm{M} \mathrm{ARA-C}$. Cultures were maintained at $37^{\circ} \mathrm{C}$ in a $95 \%$ air $/ 5 \% \mathrm{CO}_{2}$ humidified incubator for $12-21 \mathrm{~d}$ before use. For Western blotting, cells were harvested in standard RIPA lysis buffer supplemented with $1 \%$ protease inhibitor cocktail (Sigma) and $50 \mathrm{~mm} \mathrm{~N}$-ethyl maleimide (NEM).

Gel electrophoresis and Western blotting. Protein concentration was measured using the BCA assay with BSA as a standard. Usually, 10-12 $\mu \mathrm{g}$ protein sample from hippocampal cultures were mixed with reducing sample buffer, boiled, separated by SDS-PAGE (7-15\%), and transferred onto nitrocellulose membranes, following standard procedures. Membranes were incubated with primary antibody directed against ubiquitin (UO508, Sigma), Munc13 (126 102, Synaptic Systems), and Rim1 (610906, BD Biosciences) followed by washings and subsequent HRPconjugated secondary antibodies (GE-Healthcare). GAPDH (MAB374, Millipore) or tubulin (05-559, Millipore) antibodies were used to ascertain equal loading, depending on the molecular mass of the target protein to blot and/or the gel's polyacrylamide percentage. Blots were developed using ECL Plus (GE Healthcare) and imaged using the Typhoon Imaging System (GE Healthcare). For the detection of E1 ubiquitin-activating enzyme, we followed published protocols (Jha et al., 2002; Chou et al., 2008) using a polyclonal primary antibody directed against the $\mathrm{N}$ terminus of human E1-activating enzyme (PW8385, Biomol). All images of gels were cropped.

Electrophysiology. Cultured neurons on coverslips were mounted in a perfusion chamber on an inverted microscope and perfused with external solution (in mM): $\mathrm{NaCl} 134 ; \mathrm{KCl} 2.5 ; \mathrm{CaCl}_{2} 3 ; \mathrm{MgCl}_{2} 1 ; \mathrm{NaHPO}_{4} 0.34$; $\mathrm{NaHCO}_{3} 1$; glucose 20; HEPES 10; pH 7.3; 310 mOsm. All external solutions contained a final concentration of $0.1 \%$ DMSO. Electrodes were pulled from borosilicate glass capillaries (Warner) to a final tip resistance of 3.5-5.5 $\mathrm{M} \Omega$. The electrode solution consisted of (in mM): Cs methanesulfonate 100; Na-ATP 5; Na-GTP 0.3; Na-phosphocreatine 10, $\mathrm{MgCl}_{2}$ 5, EGTA 0.6, HEPES 30; pH 7.3; 295 mOsm. Inhibitory currents were recorded using a similar internal solution except for $60 \mathrm{~mm} \mathrm{CsCl}$ and $40 \mathrm{~mm}$ Cs methanesulfonate, giving a chloride reversal potential of $-19 \mathrm{mV}$. Neurons were voltage clamped at $-75 \mathrm{mV}$ for mEPSCs and mIPSCs using a Cairn Optopatch (Cairn Research) patch-clamp amplifier. Currents were low-pass filtered at $10 \mathrm{kHz}$ using the built-in 8-pole Bessel filter and acquired at $50 \mathrm{kHz}$ using a computer interface (6502E, National Instruments) and acquisition software custom-written (by FES) in LabView (National Instruments). For analysis, currents were further filtered using a software 8-pole Bessel filter. Additional analysis was conducted with Mini analysis (Synaptosoft), Detectivent (by Norbert Ankri), and OriginPro7 (OriginLab) software.

Neurons were voltage clamped in the whole-cell configuration while perfusing normal external solution. Spontaneous excitatory currents (sEPSC) were recorded in $100 \mu \mathrm{M}$ picrotoxin. Action potential independent miniature EPSCs (mEPSC) were recorded in $1 \mu \mathrm{M}$ TTX and $100 \mu \mathrm{M}$ picrotoxin, while mIPSCs were recorded in $1 \mu \mathrm{M}$ TTX, $20 \mu \mathrm{M}$ DNQX, and $50 \mu \mathrm{M}$ APV. Cells with basal mini frequencies considerably below 1 $\mathrm{Hz}$ were excluded from further study. After a $5 \mathrm{~min}$ baseline recording, the perfusion was switched to an identical external solution (control recordings) or to a solution additionally containing a $10 \mu \mathrm{M}$ UPS blocker (MG132, clasto, ziram, or Pyr-41). The protein synthesis inhibitor cyclohexamide $(40 \mu \mathrm{M})$ or high calcium (10 $\mathrm{mm}$ calcium and $5 \mathrm{~mm}$ potassium) was present, where appropriate, throughout the entire recording. To buffer intracellular calcium, cells were preincubated in $10 \mu \mathrm{M}$ BAPTA-AM for $30 \mathrm{~min}$ at room temperature followed by a baseline recording and subsequent MG132 addition.

Averages of minis were obtained by aligning (and averaging) $\sim 120$ mini events to the time point when the current had reached $50 \%$ of its peak. For frequency versus time plots, instantaneous mini frequency was obtained as the inverse of the interevent interval. The median frequency value for each cell was calculated every $60 \mathrm{~s}$, and the values were normalized to the baseline recording time. The mean group value was obtained by taking the mean of the median values across all cells. Amplitude versus time plots were obtained in a similar manner. Values for the bar graphs were obtained as simple means of values during the baseline period and a period after drug application (from minute 15 to 20 or 25). SEs were calculated using the number of cells as the statistical $n$.

$20 S$ proteasome activity assay. Dissected cortices from Sprague Dawley rats were homogenized in lysis buffer containing 50 mM HEPES, $5 \mathrm{~mm}$ EDTA, $150 \mathrm{~mm} \mathrm{NaCl}, 2 \mathrm{~mm}$ ATP, and 1\% Triton X-100 and centrifuged for $30 \mathrm{~min}$ at $50,000 \times \mathrm{g}$. The supernatant (cytosolic extract; $50 \mathrm{mg}$ of protein per sample) was used for the proteasome activity assay (Kisselev and Goldberg, 2005) by preincubating with no drug (negative control), MG132 (positive control), or ziram (sample test) followed by assessment of the three proteasomal catalytic activities using the following fluorogenic substrates: $\beta 1$, Caspase-like: 7 -amino-4methylcoumarin Z-LLE-AMC (Biomol); $\beta 2$, Trypsin-like: Boc-LSTRAMC (Sigma); $\beta 5$, Chymotrypsin-like: $N$-succinyl-LLVY-AMC (Biomol). Fluorescence values were read in a plate reader after a $2 \mathrm{~h}$ incubation period. All values were normalized to their respective negative control, and a mean was obtained for each group.

Chemicals. Unless otherwise stated, chemicals were obtained from Sigma/Fluka. The UPS blockers and other reagents used in these experiments are as follows: MG132 (Peptide Institute), clasto-lactacystin $\beta$-lactone (Boston Biochem), ziram (ChemService), 4\{4-(5-nitro-furan2-ylmethylene)-3,5-dioxo-pyrazolidin-1-yl\}-benzoic acid ethyl ester (Pyr-41; Biogenova), BAPTA-AM (AnaSpec), cycloheximide (Biomol), DNQX (6,7-dinitroquinoxaline-2,3-dione; Tocris Bioscience), APV (D(-)-2-amino-5-phosphonopentanoic acid; Tocris Bioscience).

Statistics. Statistical significance was determined using a $t$ test by comparing baseline values to values at 15 to 20 or $25 \mathrm{~min}$ - after addition of a corresponding blocker or control solution. Where applicable, other resampling simulations based on bootstrapping methods (Efron and Tibshirani, 1991) were used. Each experiment was repeated on cells from at least three separate cell cultures. Error bars indicate SEM.

\section{Results}

\section{Proteasome inhibition}

We first tested the effect of proteasome inhibition on synaptic transmission by recording activity-dependent excitatory synaptic responses. Whole-cell voltage-clamp recordings were obtained from culture hippocampal neurons in the presence of picrotoxin $(100 \mu \mathrm{M})$. After baseline spontaneous EPSCs (sEPSCs) were recorded, the proteasome inhibitor MG132 (10 $\mu \mathrm{M})$ was applied via bath perfusion. Within minutes, we observed a robust increase in sEPSC frequency (Fig. 1A,B). Both the burst frequency and the interburst interval activity increased. Furthermore, as the interburst interval activity increased, the burst duration decreased. An overall increase in cumulative sEPSC frequency was observed in neurons exposed to MG132 $(n=7)$ (Fig. $1 B$, black traces), but not in those exposed to control solution $(n=9)$ (Fig. $1 B$, gray traces). The median sEPSC frequency in MG132-treated neurons $(2.1 \pm 0.9 \mathrm{~Hz})$ was significantly greater than in control neurons (controls; $0.7 \pm 0.04 \mathrm{~Hz}$; $t$ test; $p<0.001$ ) (Fig. $1 C)$. Thus, blocking the proteasome in a cultured neuronal network induces an increase in the overall frequency of spontaneous EPSCs.

To determine whether this rapid effect in synaptic transmission was more likely due to presynaptic or postsynaptic changes, 
A

\section{Baseline, sEPSC}

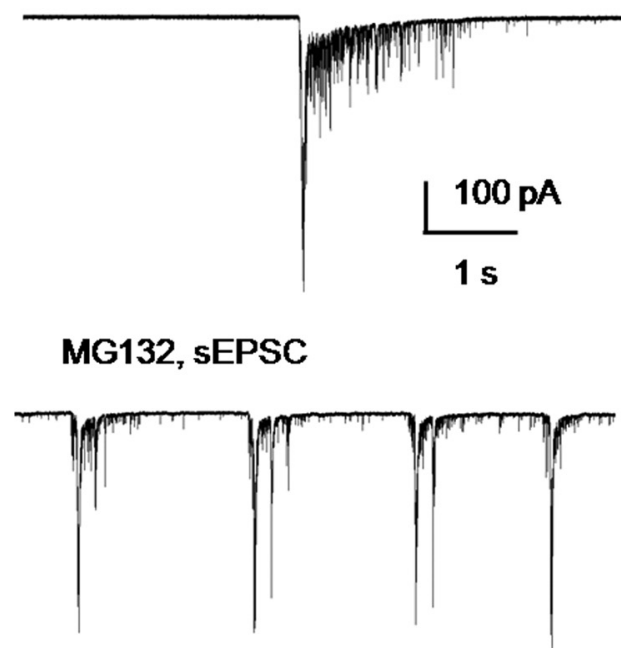

B

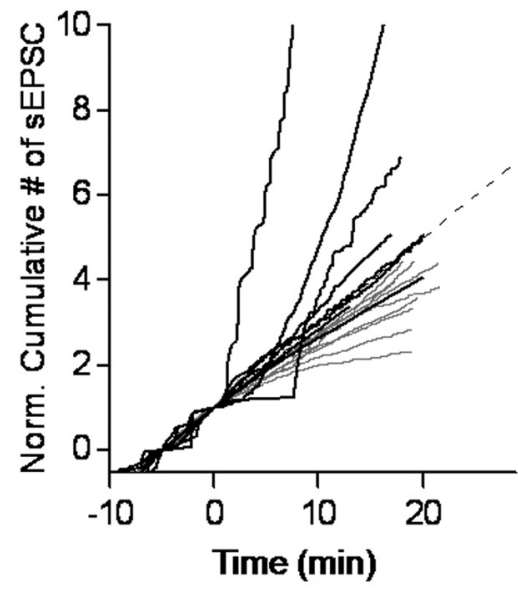

C

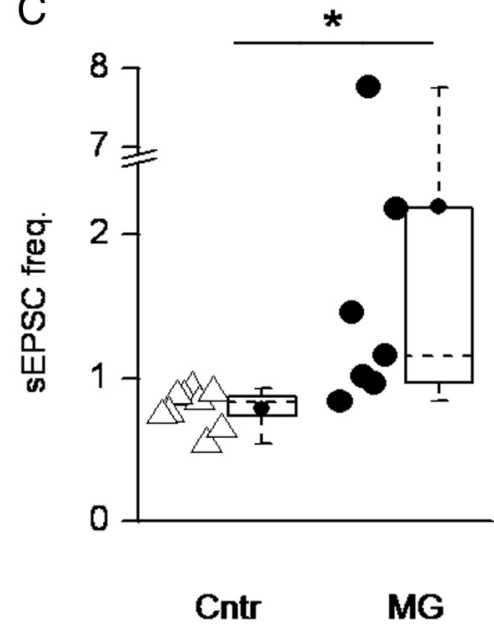

Figure 1. Proteasome inhibition increases spontaneous, activity-dependent excitatory synaptic transmission. $\boldsymbol{A}$, Representative traces of spontaneous EPSCS (sEPSC) before (top) and after (bottom) addition of proteasome inhibitor MG132 within the same neuron. Note, in this cell, an increase in both sEPSC frequency and bursts (large downward deflections) and a concomitant reduction in burst duration by about half (from $\sim 1.5 \mathrm{~s}$ to $\sim 0.7 \mathrm{~s}$ ). $\boldsymbol{B}$, Cumulative number of $\mathrm{sEPSC}$ increases more rapidly in neurons exposed to proteasome blocker (black continuous lines), than in neurons exposed to control solution (gray continuous lines). sEPSC numbers are normalized to the number of EPSCs during the baseline period-from -5 to 0 min. The number of minis was set to zero at $-5 \mathrm{~min}$, which gives a normalized value of 1 at $0 \mathrm{~min}$. A steeper rate of rise signifies a higher frequency. The dotted straight line is drawn to emphasize frequency unchanged from baseline. C, Median SEPSC frequency increases in neurons treated with proteasome blocker MG132 ( $n=7$; filled large circles), but not in the group of neurons exposed to control solution ( $C$ tr, $n=9$; open triangles) after 10 min of proteasome inhibition. Adjacent boxes represent $98 \%$ of data distribution. Filled small circle in each box represents the group mean. Dashed horizontal line in each box represents the group median. Dashed error bars are maximum and minimum values. Same group of cells as $\boldsymbol{B}$. Recordings were done in the presence of picrotoxin to block inhibitory currents. ${ }^{*} t$ test $p<0.001$.

A

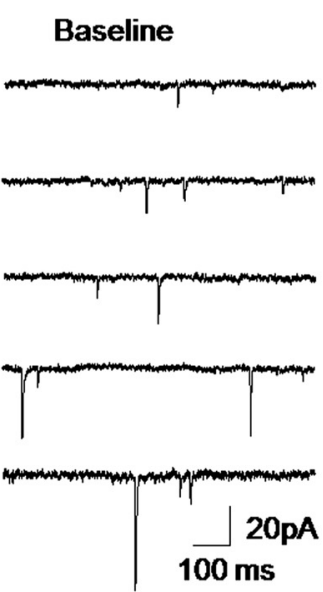

B $\mathrm{mE}$
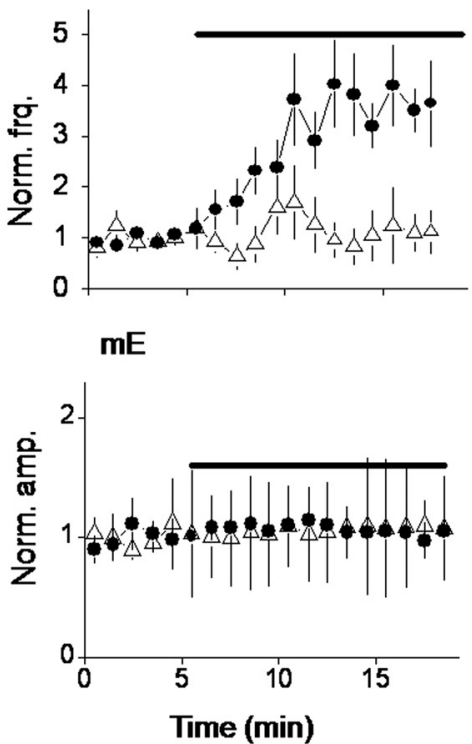

C $\mathrm{ml}$
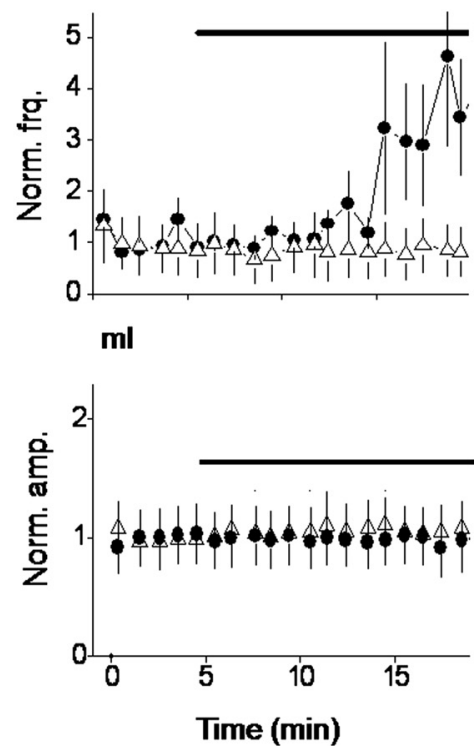

Figure 2. Proteasome inhibition increases excitatory and inhibitory neurotransmitter release. $\boldsymbol{A}$, Representative traces of excitatory minis (mEPSCs) recorded in picrotoxin and TTX from the same neuron before (left) and after (right) addition of MG132. Note the increase in frequency of quantal release in response to proteasome inhibition. $\boldsymbol{B}$, Normalized median average of mEPSC frequency (top; control $\triangle, n=6 ; \mathrm{MG132}, n=8 ; p<0.05$ ) and mEPSC amplitude (bottom; same cells) over time. Note the strong increase in mini frequency within the first 5 min of proteasome inhibition. No change in amplitude is observed. C, Normalized median average of mIPSC frequency (top; control $\triangle, n=5 ;$ MG132,$n=6 ; p<0.05$ ) and mIPSC amplitude (bottom; same cells) over time, recorded in picrotoxin and TTX. Black line, Application of MG132 or control solution. mE, MEPSCs; ml, mIPSCs. Error bars are \pm SEM.

we measured the frequency and amplitude of miniature postsynaptic events (minis) in the presence of TTX $(1 \mu \mathrm{M})$ to block action potentials. The baseline frequency of the miniature EPSCs (mEPSCs) varied considerably from cell to cell and across cultures (range: 1.5-19.1 Hz; median: $6.4 \pm 1.2 \mathrm{~Hz}$ ). We therefore compared minis from the same cell before and after drug application. Figure $2 \mathrm{~A}$ shows exemplar traces taken from a neuron perfused with control solution followed by application of $10 \mu \mathrm{M}$ MG132. The proteasome inhibitor triggered an increase in mini frequency without any apparent change in mini amplitude. When switching 
from one control solution to an identical control solution $(n=6)$ (Fig. $2 B$, top; open triangles, normalized to baseline), no significant changes in mini frequency $(2 \pm 0.6 \mathrm{~Hz}$ to $3 \pm 1.6 \mathrm{~Hz}$ ) or mini amplitude $(16 \pm 1.7 \mathrm{pA}$ to $15.7 \pm 6.3 \mathrm{pA})$ were observed. However, when switching from a control solution to a solution containing $10 \mu \mathrm{M}$ MG132 (Fig. 2 B, black circles, normalized to baseline) mini frequency rapidly increased approximately threefold (from $3.5 \pm 0.05 \mathrm{~Hz}$ to $12.8 \pm 0.11 \mathrm{~Hz}$, $n=8 ; p<0.05$ ), while mini amplitude (from $16.2 \pm 2.9 \mathrm{pA}$ to $17.6 \pm 4.6 \mathrm{pA}$ ) (Fig. $2 B$, bottom) and mini kinetics (rise time from $1 \pm 0.1 \mathrm{~ms}$ to $1 \pm 0.1 \mathrm{~ms}$; decay from $2.7 \pm 0.4 \mathrm{~ms}$ to $2.4 \pm 0.2 \mathrm{~ms}$ ) remained unchanged compared to control (Fig. 3). Changes in mini frequency are generally thought to arise from changes in the number of vesicles released per unit time, i.e., presynaptic changes. Alterations in mini amplitude, on the other hand, are interpreted as changes in the number of neurotransmitter receptors activated, i.e., postsynaptic changes. The change in frequency only thus suggests a presynaptic site of action.

MG132 has been reported to block cellular calpains in addition to the proteasome (Mailhes et al., 2002). We thus repeated these experiments with the more specific (and considerably more expensive) proteasome blocker clasto-lactacystin $\beta$-lactone (clasto; $10 \mu \mathrm{M})$. The results obtained with clasto were consistent with the ones obtained with MG132. The mini excitatory frequency of $3.7 \pm 0.6 \mathrm{~Hz}$ at baseline increased to $11.5 \pm 3.3 \mathrm{~Hz}$ after clasto perfusion with no change in mini amplitude $(n=4$; threefold increase) (supplemental Fig. 2, available at www.jneurosci.org as supplemental material). Since MG132, but not clasto, has been reported to be a reversible proteasome inhibitor (Sutovsky et al., 2003), we tested whether the increase in mini frequency could be reversed within a similar timeframe. However, a 10 min washout of MG132, did not affect the increase in neurotransmitter release (data not shown).

To determine whether UPS inhibition would trigger a similar increase in inhibitory neurotransmission, experiments were conducted in the absence of picrotoxin, while blocking excitatory AMPA and NMDA receptors with DNQX $(20 \mu \mathrm{M})$ and APV (100 $\mu \mathrm{M})$, respectively, and blocking action potentials with TTX. Cells were voltage clamped at $-75 \mathrm{mV}$ using an internal solution that produced a chloride reversal potential of $-19 \mathrm{mV}$ (see Materials and Methods). Miniature IPSCs (mIPSCs) were thus measured as inward currents (Fig. 2C). The frequency of mIPSCs was stable during a baseline period then rapidly increased severalfold in response to application of the proteasome inhibitor MG132 (from $2.3 \pm 0.6 \mathrm{~Hz}$ to $7.4 \pm 1.9 \mathrm{~Hz}, n=8 ; p<0.05$ ). As was the case for excitatory minis, the rapid increase in mIPSC frequency was not accompanied by an increase in amplitude (from $17.4 \pm$ $3.6 \mathrm{pA}$ to $17.2 \pm 3.6 \mathrm{pA}$ ), and no changes in the kinetics were observed (rise time from $2.8 \pm 0.3 \mathrm{~ms}$ to $2.5 \pm 0.7 \mathrm{~ms}$; decay time from $8.3 \pm 0.9 \mathrm{~ms}$ to $8.6 \pm 1.1 \mathrm{~ms}$ ) (Fig. 3 ). These findings indicate that the UPS regulates presynaptic release not only at excitatory but also at inhibitory synapses. We conclude that the UPS modulates neurotransmitter release and that this effect is
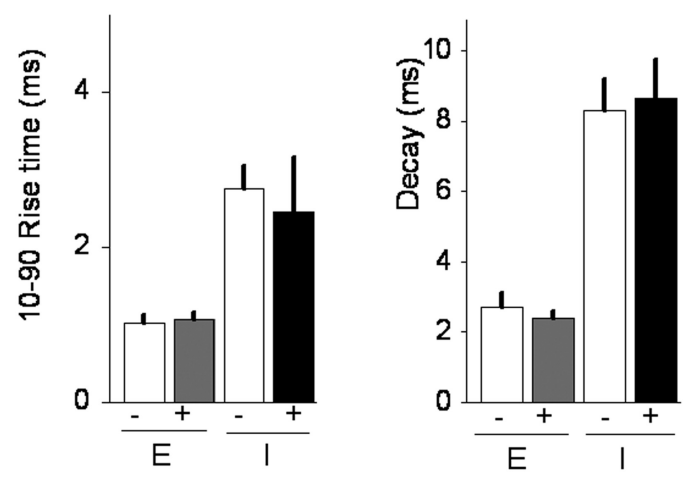

ml
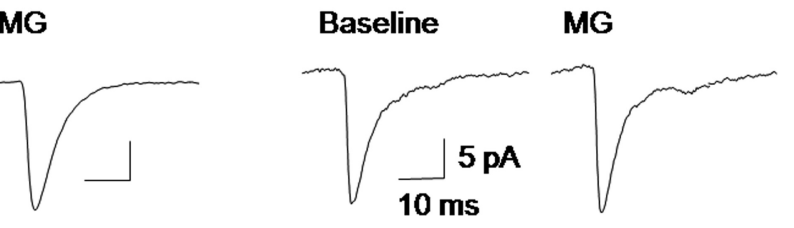

Figure 3. Proteasome inhibition has no effect on excitatory and inhibitory neurotransmitter release kinetics. $\boldsymbol{A}$, Proteasome
inhibition does not affect mEPSC and mIPSC amplitude, $10-90 \%$ rise time or decay time. Median values are plotted before $(-)$ and after (+) MG132 application. Error bars are \pm SEM. $\boldsymbol{B}$, Average of $\sim 120$ minis for mEPSC control and after MG132 (left traces), and for mIPSC control and after MG132 (right traces). mE or E, mEPSCs; ml or l, mIPSCs. Same group of cells as shown in Figure 2.

presynaptic, since only the frequency, but not the amplitude, or the kinetics are affected at both excitatory and inhibitory synapses.

\section{Mechanism}

To test the mechanism by which proteasome inhibitors mediate this surprisingly fast increase in presynaptic vesicle fusion, we explored proteasome-mediated pathways known to be involved in neuronal and synaptic physiology. Since proteasome inhibition prevents the degradation of proteins, we hypothesized that the proteasome-dependent increase in neurotransmitter release observed here (Figs. 1, 2) was mediated by extending the half-life of a protein involved in the regulation of vesicle fusion by inhibiting its degradation. Using Western blot analysis of hippocampal cultures and a primary antibody against ubiquitin, we established that, as expected, blocking the proteasome for up to $2 \mathrm{~h}$ led to an accumulation of ubiquitinated proteins. The median intensity of the ubiquitin signal was increased 50\% in bands from MG132 preincubated neurons compared to those from control neurons $(n=4 ; p<0.01)$ (Fig. $4 A)$. This is consistent with the notion that the levels of certain presynaptic proteins also increase following proteasomal blockade. Indeed, at the Drosophila NMJ, proteasome inhibition leads to an accumulation of the vesicle priming protein Dunc-13 and this accumulation is necessary for an increase in synaptic transmission (Speese et al., 2003). However, a study in rodent hippocampal cultures found no evidence of proteasomal regulation of the mammalian homolog Munc-13 (Kalla et al., 2006). Consistent with the latter study and potentially indicating important species-specific differences in the regulation of synaptic transmission, we failed to detect any consistent increase in Munc-13 levels in cultures that were treated with proteasome inhibitors (Fig. 4B). An additional membrane protein that modulates vesicle fusion is Rab3 interacting molecule 1 (RIM1) (Schoch et al., 2002; Kiyonaka et al., 2007). Rim1 has been reported to undergo polyubiquitination via the F-Box-type E3 ubiquitin enzyme named scrapper (Yao et al., 2007). If scrap- 


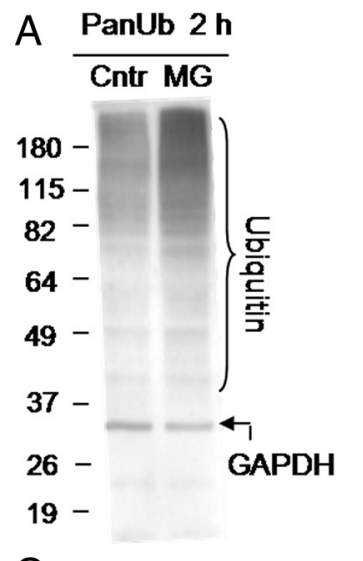

C $10 \mathrm{~m}$ Cntr $\mathrm{MG}$
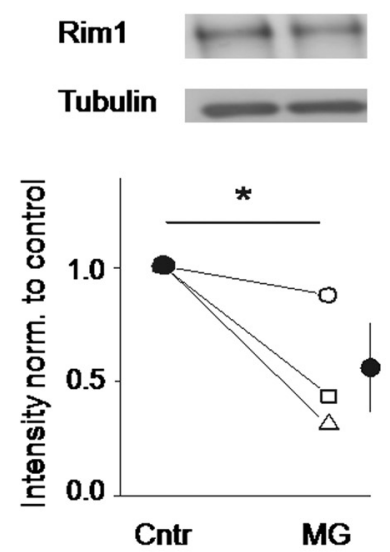

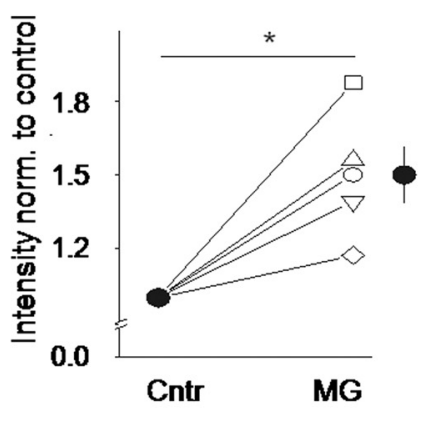

2 h Cntr MG
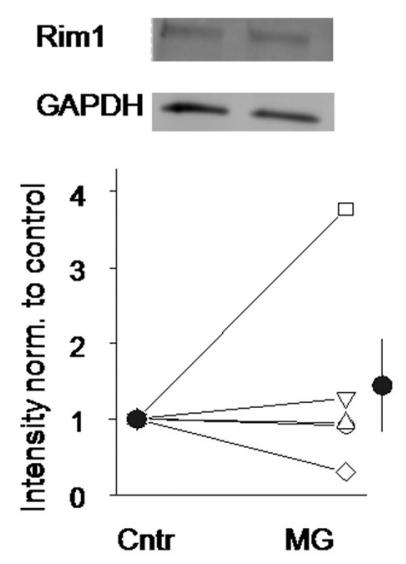

B
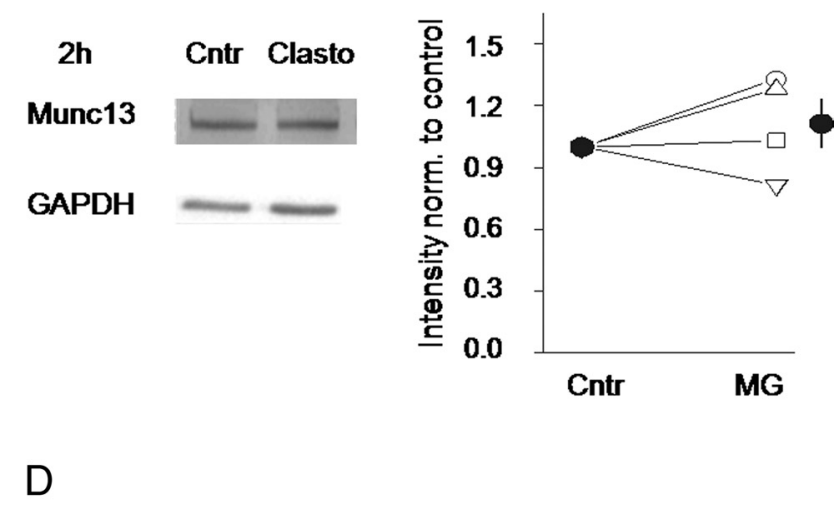

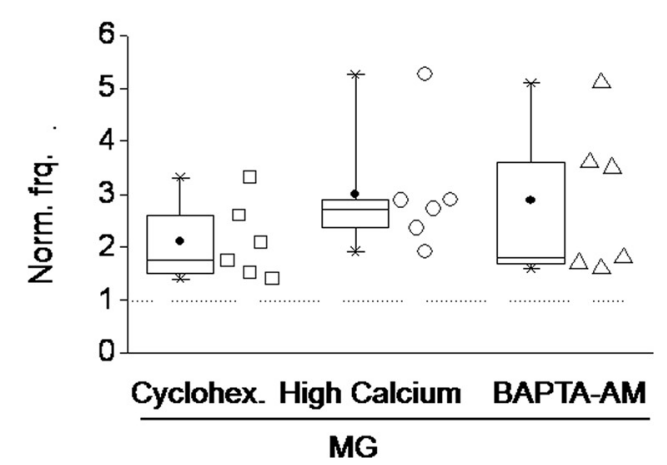

Figure 4. Tested mechanisms that could mediate an increase in neurotransmitter release via UPS. $\boldsymbol{A}$, Left, Representative immunoblot confirms an accumulation of ubiquitinated proteins after blocking the proteasome. Neuronal cultures were incubated for 120 min without (Cntr) or with (MG) the proteasome blocker MG132. Monoclonal antibodies that recognize all ubiquitin forms (PanUb) were used to quantify the ubiquitinated state of neurons. Standard masses are illustrated in kilodaltons (kDa). Right, Median intensity (filled black circle) from a total of four independent experiments (open symbols), confirms a statistically significant increase in ubiquitinated proteins in those neurons exposed to MG132, compared to a control group ( $n=4, p=0.01$ ). $\boldsymbol{B}$, Levels of the synaptic-vesicle priming protein, Munc-13, do not increase in rat hippocampal neurons after UPS blockage. Western blot analysis of cultures treated for $2 \mathrm{~h} \pm \mathrm{Clasto}$. Left, Representative immunoblot. Right, Immunoblot intensity analysis as in $\boldsymbol{A}(n=4)$. $\boldsymbol{C}$, Levels of the synaptic-vesicle-fusion regulatory protein Rim1 do not increase after proteasome inhibition. Left top, Representative immunoblot after incubating cells for $10 \mathrm{~min} \pm$ MG132. Left bottom, Immunoblot intensity analysis as in $\boldsymbol{A}(n=5 ; p<0.01)$. Right top and bottom, Representative immunoblot and median results using anti-Rim1 antibody in neurons preincubated with or without $10 \mu \mathrm{m}$ MG132 for $2 \mathrm{~h}$. Rest is same as for left panel. Note no consistent change in Rim1 levels. $\boldsymbol{D}$, The increase in excitatory mini frequency by proteasome blockers is not protein-synthesis or calcium dependent. Neurons treated with the protein synthesis inhibitor cycloheximide (left; Cyclohex.; $<<0.01 ; n=$ 6), exposed to high calcium (middle; $n=6 ; p<0.001$ ) or with strongly buffered intracellular calcium (right; BAPTA-AM; $n=6 ; p<0.01$ ) still elicited a significant increase in mini frequency when applying MG132 (see Materials and Methods for details). Dashed line illustrates (normalized) baseline frequency. Plot description as in Figure 1C. Error bars are \pm SEM. Cntr, Control; MG, MG132; Clasto, clasto-lacatacystin $\beta$-lactone. Western blots: 10\% PAGE for ubiquitin; 7\% for Rim1. Loading controls were assessed with antibodies against the housekeeping enzyme GAPDH or tubulin.

per (also known as FBXL20) is inactivated, Rim1 levels increase leading to enhanced synaptic transmission (Yao et al., 2007). In our hands, however, Rim1 levels did not increase after $10 \mathrm{~min}$ or even after $2 \mathrm{~h}$ of proteasome blockade $(n=3)$. In fact, we observed a small, but statistically significant decrease in Rim1 levels at $10 \mathrm{~min}$ of proteasome inhibition. After $2 \mathrm{~h}$, we did observe a rather large increase in a single experiment, but a decrease in the others, resulting in no significant change (Fig. $4 C$ ). It thus appears the mini-frequency increase reported here does not depend on altered degradation of (at least these two) synaptic proteins (see below).

If proteasome inhibitors elicit an increase in mini frequency by blocking the degradation of particular proteins, then these proteins likely are constitutively degraded in the unaltered system. Consequently, if steady-state protein levels are to be maintained, such proteins must be synthesized on a similar time scale. In fact, protein synthesis and degradation have been reported to bidirectionally regulate long-term potentiation (LTP) (Fonseca et al., 2006; Karpova et al., 2006; Dong et al., 2008). Although inhibition of protein synthesis does not appear to affect basal synaptic transmission within minutes (Li et al., 1998), we nevertheless tested whether inhibition of protein synthesis interferes with the UPS-induced increase in mini frequency. Hippocampal cultures were incubated with the protein synthesis inhibitor cycloheximide $(40 \mu \mathrm{M})$. Interestingly, UPS inhibition still elicited an increase in mini frequency in the presence of protein synthesis inhibitors (from $4.1 \pm 1 \mathrm{~Hz}$ to $8.3 \pm 1.6 \mathrm{~Hz} ; n=6 ; p<0.01$ ) (Fig. $4 D)$. We conclude that early and fast modulation of synaptic transmission by the proteasome is not affected by protein synthesis.

We next tested the influence of calcium on mini-frequency increases. Even small increases in intracellular calcium can increase neurotransmitter release (Lou et al., 2005), and it has been suggested that proteasome inhibition-mediated increases in mini frequency are abolished in the complete absence and in the presence of high extracellular calcium levels (Yao et al., 2007). We 
A

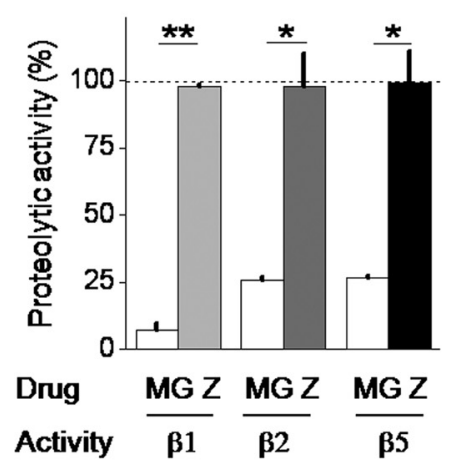

C
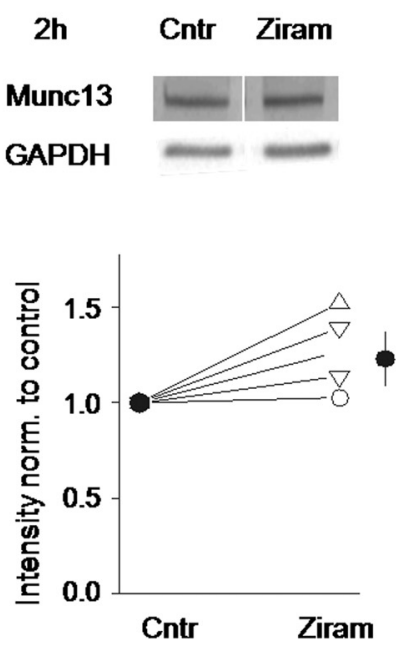

B

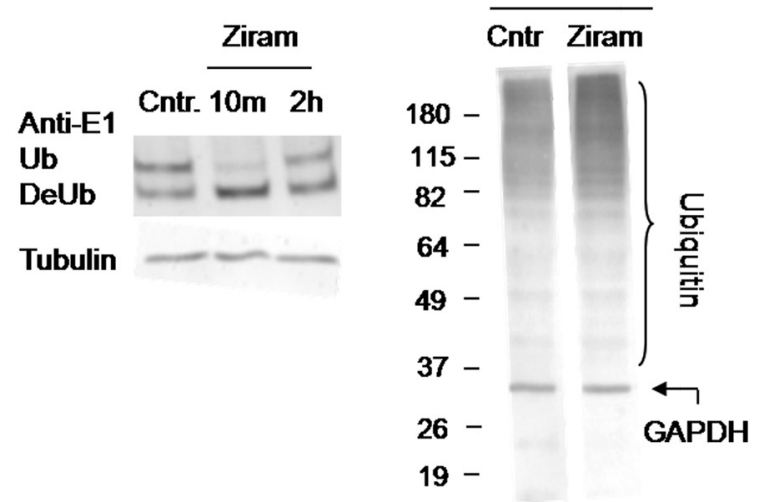

D
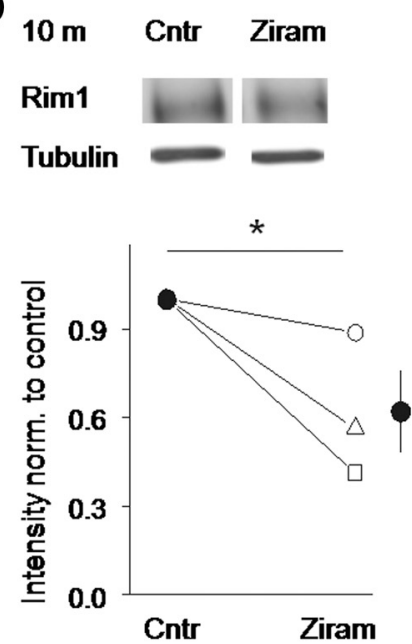
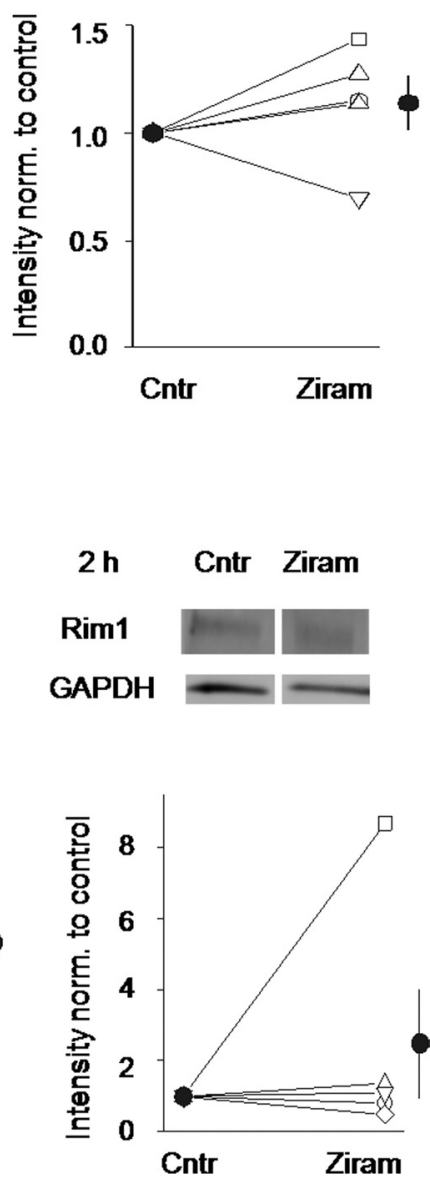

Figure 5. Testing the effect of the ubiquitin proteasome system through an alternative checkpoint: the E1 ubiquitin-activating enzyme. $\boldsymbol{A}$, Left, The E1 inhibitor, ziram, does not directly block proteasomal activity. Ziram's effect on proteasome activity was assessed by means of applying the 20 S proteasome activity assay and testing the three proteasomal catalytic activities ( $\beta 1, \beta 2$, and $\beta 5$; see Materials and Methods). Note that ziram (Z) does not inhibit any of the three proteolytic activities of the proteasome, while MG (MG132) does. Right, Ziram blocks the E1 enzyme by preventing its ubiquitination. Immunoblot (5\% PAGE) shows that the ubiquitinated fraction of E1 is strongly decreased compared to the nonubiquitinated fraction. This is most apparent after the 10 min preincubation. $\boldsymbol{B}$, E1-enzyme inhibitor ziram does not increase protein ubiquitination levels. Left, Representative Western blot (10\% PAGE) developed with anti-ubiquitin antibodies of hippocampal cultures treated for $2 \mathrm{~h}$ with ziram. Standard masses are illustrated in kDa. Right, Median ubiquitin intensity (filled black circles) from five independent experiments (open symbols). Neither Munc13 (C) nor Rim1 (D) levels increase after E1 inhibition. A 120 min incubation of neurons with the E1 blocker ziram, leads to no change in levels of Munc13 or Rim1. Rim1 levels do not increase after a 10 min exposure to ziram, which coincides with ziram's strongest E1 inhibition and the increase in minis. Top, Representative Western blots. The lower panels indicate median intensity values for each protein as in $\boldsymbol{B}$. Monoclonal antibodies against the housekeeping enzyme GAPDH or tubulin were used as loading controls. ${ }^{*} t$ test $p<0.05,{ }^{* *} t$ test $p<0.001$. Cntr, Control. Western blots, PAGE: $5 \%$ for E1; $7 \%$ for Rim1; $10 \%$ for Munc- 13 and ubiquitin.

thus first tried to record minis in the absence of extracellular calcium, but could not obtain stable recordings (data not shown). Next, we tested whether high extracellular calcium levels (10 mM) would occlude the proteasome inhibition-induced mini frequency increase. In contrast to Yao et al. (2007), we found that MG132 increased mini frequency approximately threefold even in the presence of high external calcium concentrations (10 mM; $5.9 \pm 1.8$ to $15.8 \pm 5.0 \mathrm{~Hz}, n=6$; $p<0.01$ ) (Fig. $4 D$ ). To investigate the role of intracellular calcium increases, we loaded hippocampal cultures with the calcium chelator BAPTA-AM. Application of MG132 to BAPTA-AM preloaded neurons still evoked a rapid and robust increase in mini frequency (from 2.0 $\mathrm{Hz} \pm 0.22$ to $4.6 \mathrm{~Hz} \pm 0.9, n=6 ; p<0.01$ ) (Fig. $4 D$ ). We conclude that the observed increase in mini frequency is not occluded by high extracellular calcium levels and that it is also independent of increases in intracellular calcium.

Together, these data show that the fast increase in mini frequency we observe after proteasome inhibition is not mediated by previously reported mechanisms including the active-zone proteins Munc-13 and Rim1, or alternative pathways such as protein synthesis, and is calcium independent.

\section{E1 inhibition}

Our hypothesis that the strong and fast increase in neurotransmitter discharge following proteasome inhibition is mediated by the increased half-life of a synaptic regulator was mainly based on the observation that proteasome inhibition leads to a significant accumulation of ubiquitinated proteins (Fig. $4 A$ ). We decided to further test this hypothesis by inhibiting the UPS at a different checkpoint. We reasoned that inhibition of the universal E1 ubiquitin-activating enzyme should block all subsequent protein ubiquitination events. Moreover, since E1 inhibition does not directly block proteasomal activity, preubiquitinated proteins should still be degraded and should not accumulate. An increase in mini frequency that depends on preubiquitinated proteins should thus be prevented or at least delayed. To test this, we made use of two structurally unrelated inhibitors of the E1-ubiquitin- 
A

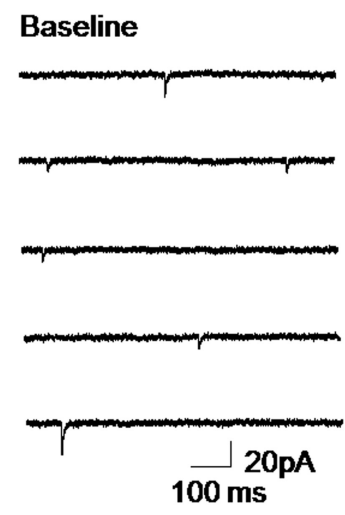

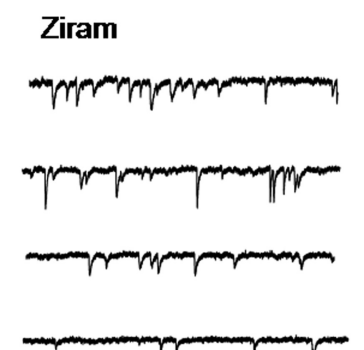

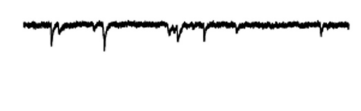

B

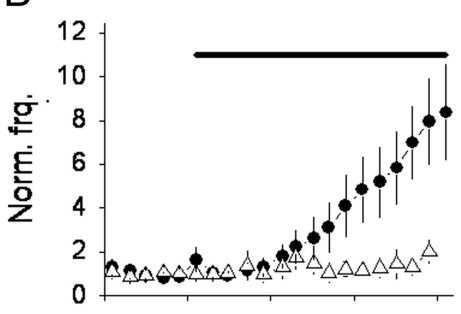

$\mathrm{mE}$

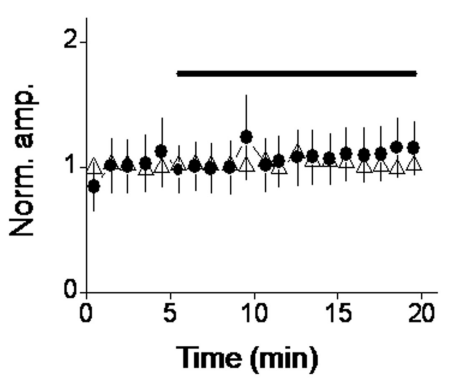

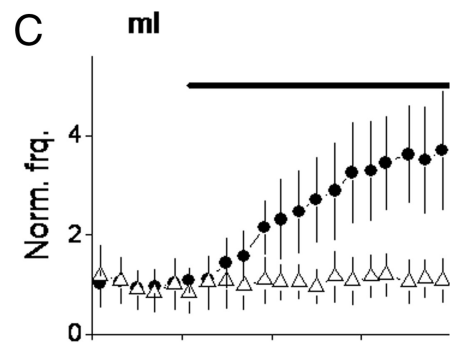

ml

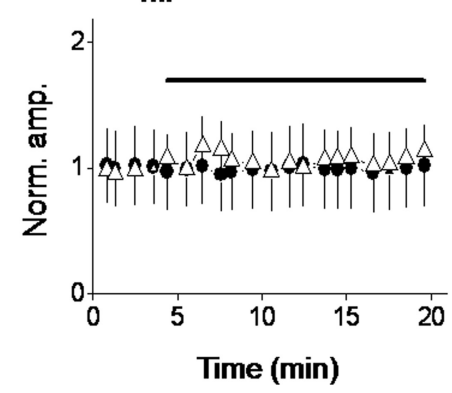

Figure 6. E1 ubiquitin-activating enzyme inhibition increases excitatory and inhibitory neurotransmitter release. $A$, Representative traces of excitatory minis (mEPSCs) before (left) and after (right) addition of ziram. Note the increase in $\mathrm{mEPSC}$ frequency, but not amplitude, in response to E1 inhibition. $\boldsymbol{B}$, Normalized running averages from neurons exposed to ziram show an increase in $\mathrm{mEPSCs}(\mathrm{mE})$ frequency (top; control, open triangles $n=7 ;$ ziram, filled circles $n=6 ; p<0.05)$. C, The frequency of $\mathrm{mIPSCs}(\mathrm{ml}$ ) also increases in response to ziram exposure (top; control, open triangles $n=5 ;$ ziram, filled circles $n=6 ; p=0.01$ ). No change in $\mathrm{mE}$ or $\mathrm{ml}$ amplitude was observed ( $\boldsymbol{B}$ and $\boldsymbol{C}$; bottom).
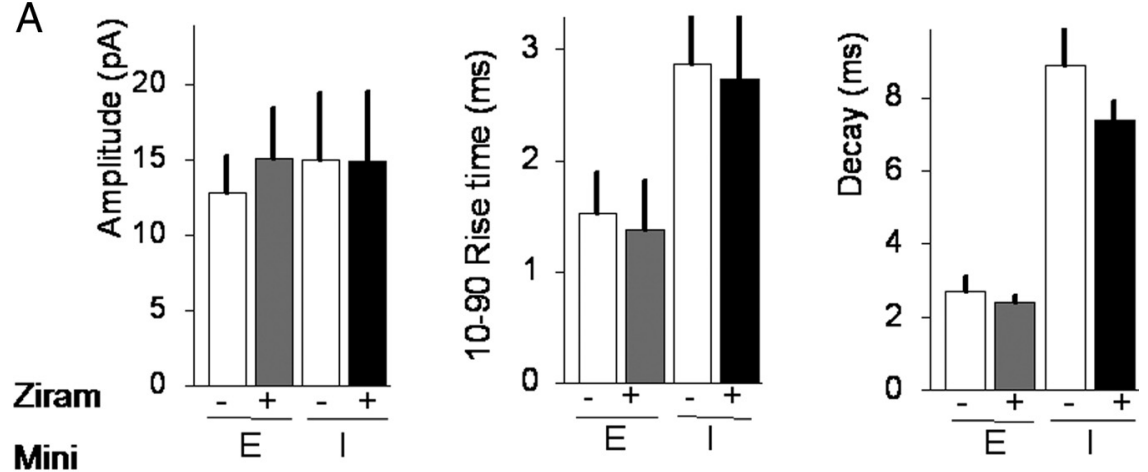

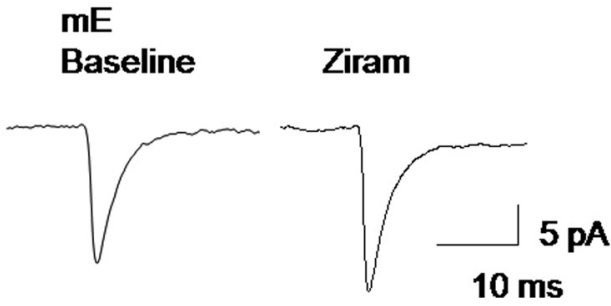

Figure 7. E1 inhibition has no effect on excitatory and inhibitory neurotransmitter release kinetics. $A$, E1 inhibition does not affect mini amplitude (left), 10-90 rise time (middle), or decay time (right). Median values are plotted before $(-)$ and after (+) ziram application. E, Excitatory mini currents; I, inhibitory mini currents. Error bars are \pm SEM. $\boldsymbol{B}$, Averages of $\sim 120$ minis for mEPSC control and after ziram. Same group of cells as shown in Figure 6.

activating enzyme, the fungicide ziram (Chou et al., 2008) and Pyr-41/UBEI-41 (Yang et al., 2007).

We first confirmed (Chou et al., 2008) that ziram does not inhibit the proteasome itself by measuring $\beta 1, \beta 2$, and $\beta 5$ proteolytic activities of the proteasome in rat brain cytosol in the absence and presence of ziram using fluorogenic substrates (see Materials and Methods). As predicted, ziram did not inhibit these enzymatic activities but they were efficiently blocked by MG (activities relative to no drug control: $\beta 1$ : MG $7 \pm 1 \%$, ziram
$98 \pm 2.6 \% ; \beta 2:$ MG $25.7 \pm 12 \%$, ziram $98 \pm 1.5 \%$; and $\beta 5:$ MG $25.6 \pm 12 \%$, ziram $99.5 \pm 1 \%$ ) (Fig. $5 A$, left). We also confirmed that ziram indeed inhibits active site ubiquitination of the E1 enzyme in mammalian neurons by comparing levels of ubiquitinated and nonubiquitinated forms of E1 on Western blots (Jha et al., 2002; Chou et al., 2008). Inhibition appeared stronger after $10 \mathrm{~min}$ than after $2 \mathrm{~h}$ possibly indicating breakdown of ziram or compensatory mechanisms (Fig. 5A, right) ( $n=3$ independent cell types). To confirm that ubiquitinated proteins do not accumulate in response to E1 inhibition, we compared control cultures and cultures treated with ziram using Western blot analysis and antibodies directed against ubiquitin. As expected, ziram was ineffective in eliciting a significant change in the level of ubiquitinated proteins (Fig. 5B). These results show that while proteasome blockers cause a significant accumulation of ubiquitinated proteins (Fig. $4 A$ ), E1 enzyme blockers do not. Similar to the results with proteasome inhibitors described above, blocking the E1 enzyme with ziram did not exert an increase on Munc-13 or Rim1 levels (Fig. 5C,D). In fact, as was the case for proteasome inhibition, a small but statistically significant decrease in Rim1 levels was observed at 10 min of $\mathrm{E} 1$ inhibition, which returned to control levels within $2 \mathrm{~h}$ of inhibition.

Alternative hypothesis

To test whether the accumulation of ubiquitinated protein(s) is indeed necessary for an increase in mini frequency, we blocked the E1 enzyme, which blocks ubiquitination, but not the degra- 
dation of ubiquitinated proteins. Since ubiquitinated proteins are thus not accumulating, we expected to observe no change or a decrease in mini frequency. Surprisingly, ziram strongly increased neurotransmitter release of both excitatory (from $2.2 \pm 1.4 \mathrm{~Hz}$ to $14.7 \pm 8.9 \mathrm{~Hz}$, $n=6 ; p<0.05$ ) and inhibitory (from $3.8 \pm 0.9 \mathrm{~Hz}$ to $13.7 \pm 3.4 \mathrm{~Hz}, n=6$; $p=0.01)$ miniature postsynaptic currents (Fig. 6). Ziram application did not exert a change on mEPSC amplitude (from $12.8 \pm 2.5 \mathrm{~Hz}$ to $15.0 \pm 3.3 \mathrm{~Hz}, n=6$ ) [Figs. $6 B$ (bottom), 7], nor did it affect time course (rise time from $1.5 \pm 0.4 \mathrm{~ms}$ to $1.4 \pm 0.4 \mathrm{~ms}$; decay from $2.6 \pm 0.4 \mathrm{~ms}$ to $3.1 \pm 0.7 \mathrm{~ms}, n=6$ ) (Fig. 7). Furthermore, mIPSC amplitude $(15 \pm 4.5 \mathrm{pA}$ to $14.9 \pm 4.7 \mathrm{pA}$ ) [Figs. $6 C$ (bottom), 7] and kinetics (rise time from $2.9 \pm 1.3 \mathrm{~ms}$ to $2.7 \pm 0.9 \mathrm{~ms}$; decay time from $8.9 \pm 1.3$ $\mathrm{ms}$ to $7.4 \pm 0.5 \mathrm{~ms}, n=6$ ) were not affected (Fig. 7). Similar results were obtained with the structurally unrelated E1-inhibitor Pyr41/UBEI-41 (mini frequency from $6.2 \mathrm{~Hz} \pm 1.7$ to $31.0 \mathrm{~Hz} \pm$ 5.7, $n=6 ; p=0.01$ ) (supplemental Fig. 2, available at www.jneurosci.org as supplemental material). We conclude that the UPS can exert rapid and potent control over neurotransmitter release and hypothesize that this effect is not exclusively mediated via protein degradation (protein turnover), but also through the dynamic ubiquitination of target proteins. This hypothesis is consistent with the lack of global increases in the level of polyubiquitinated proteins observed after a $10 \mathrm{~min}$ preincubation with either a proteasome blocker or an E1 inhibitor (Fig. 8A). While we cannot exclude an increase that is below our detection level and/or an increase that affects only a small fraction of the proteins, our data are consistent with the notion that global increases in the level of ubiquitinated proteins do not correlate with increases in mini frequency (see Discussion). In Figure $8 B$, we present a model wherein both protein degradation and dynamic ubiquitination modulate active zone regulatory proteins.

\section{Discussion}

Protein ubiquitination is a posttranslational modification that marks proteins for degradation thereby modulating their halflife, and it can also dynamically modulate protein function. Protein degradation serves to purge the cell of damaged (e.g., misfolded or oxidized) proteins and to reduce the levels of proteins that are no longer required or would be deleterious for the current state of the cell (e.g., cell cycle regulators) (Ciechanover and Schwartz, 2004; Fang and Weissman, 2004). Dynamic and reversible protein ubiquitination, on the other hand, serves as a posttranslational modification that controls trafficking, interac-

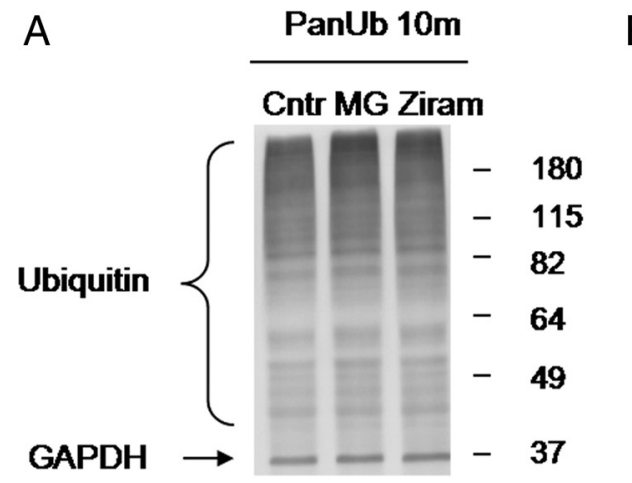

$B$

Figure 8. Dynamic ubiquitination as an alternative pathway for synaptic protein modulation. A, Short-term inhibition of either the proteasome or $\mathrm{E} 1$ enzyme does not accumulate ubiquitinated proteins. Representative immunoblot using anti-ubiquitin antibody against proteins from neurons incubated for 10 min with the proteasome blocker MG132 (MG) or the E1 inhibitor ziram. No change in global protein ubiquitination levels is observed compared to control (C) conditions. Standard masses are illustrated in $\mathrm{kDa}$. B, Median normalized intensity levels of three independent anti-ubiquitin immunoblots (thick black lines) together with the Note lack of systematic accumulation of ubiquitinated proteins. GAPDH (arrow) serves as a loading control. Error bars are \pm SEM. , Working hypothesis: protein degradation ( $\Delta$ lifetime) and dynamic protein ubiquitination ( $\Delta$ activity) are both responsible for the fast and strong increase in mini frequency. E1, E2, E3, Enzymes of the ubiquitination cycle; $\mathrm{Ub}$, ubiquitin; $\mathrm{S}$, substrate (note that the shape indicates potentially different activity forms). Arrows on the right indicate expected changes in global levels of proteins in response to inhibition of either proteasome (open arrows) or E1 (black arrows). Blocking the proteasome will trigger an accumulation of ubiquitinated substrate proteins (S) that are no longer degraded (indicated by open arrows on the right side of the figure). As free ubiquitin gets trapped in the polyubiquitinated proteins, new protein ubiquitination can no longer happen, thus ding to a decrease in the ubiquitinated form of dynamically ubiquitinated proteins. In contrast, blocking E1 activity will not block the degradation of ubiquitinated proteins, but will also inhibit dynamic ubiquitination and increase the level of deubiquitinated proteins. Since the physiological effect of proteasome and $\mathrm{E}$ inhibition is the same, it seems likely that a decrease in dynamic protein ubiquitination is responsible for the increase in mini frequency. tion partners, and the "activity state" of proteins, reminiscent of other posttranslational modifications such as protein phosphorylation (Hicke, 2001; Conaway et al., 2002; Mukhopadhyay and Riezman, 2007). Based on previous reports (Speese et al., 2003; Zhao et al., 2003; Yao et al., 2007), we originally hypothesized that polyubiquitinated proteins that accumulate after blocking the proteasome would have an increased half-life, which would in turn affect neurotransmitter release. To test this, we blocked the proteasome system at two critical points, expecting opposing effects: Blocking the proteasome proper should increase the halflife of synaptic proteins that accumulate in the polyubiquitinated 
state. In contrast, inhibiting the universal E1 enzyme should lead to no accumulation and maybe even a decrease in polyubiquitinated proteins. Our prediction was that E1 inhibition should thus either not affect synaptic transmission or alter it in the opposite direction (Fig. 8 B).

To block the proteasome, we selected two structurally unrelated and widely used proteasome blockers: MG132 and clastolactacystin $\beta$-lactone. To inhibit E1, we took advantage of two novel and also structurally unrelated E1 blockers: ziram and Pyr41/UBEI-41. Ziram, a widely used fungicide, has recently been shown to potently inhibit E1-ubiquitin ligase activity (Chou et al., 2008). The thiol group of this zinc dimethyldithiocarbamate likely competes with ubiquitin for E1's cysteine group, thus preventing the activation of ubiquitin (Fig. 5A). Although ziram's effects on E2s or E3s have not been investigated, we show here that it does not directly inhibit the proteasome (Fig. $5 \mathrm{~A}$ ), and that it does not trigger a significant accumulation of ubiquitinated proteins in neurons (Figs. 5B, $8 A$ ). Pyr-41, a pyrazone, covalently modifies the active site of E1, but not the E2 ubiquitin-conjugating enzymes, the proteasome, or caspases (Yang et al., 2007). However, while both of these compounds clearly do inhibit E1activating enzyme, they have not been fully characterized and may have some off-target effects. For example, Pyr-41/UBEI-41 has been shown to augment sumoylation. While a more extensive study of off-target effects will be informative, the use of two structurally unrelated compounds that yield the same effect lessens the likelihood that these are solely due to off-target actions.

Blocking of either the proteasome (Figs. 1, 2; supplemental Fig. 1, available at www.jneurosci.org as supplemental material) or the E1 ubiquitin-activating enzyme (Fig. 6; supplemental Fig. 2, available at www.jneurosci.org as supplemental material) strongly and rapidly increased neurotransmitter release. This prompted us to reevaluate our original hypothesis that an accumulation of nondegraded, possibly polyubiquitinated proteins is responsible for this increase. Inspection of the ubiquitination cycle (Fig. $8 \mathrm{~B}$ ) reveals that inhibition of the proteasome versus the E1 enzyme will have opposing effects on the levels of polyubiquitinated proteins (note arrows on right): proteasome inhibition will increase the level of proteins ready for degradation, while E1 inhibition (in the absence of proteasomal blockade) will still allow previously ubiquitinated proteins to be degraded. On the other hand, inhibitors of either proteasome or E1 will trigger a general deubiquitination of reversibly ubiquitinated proteins, as activated ubiquitin—provided through the cascade of E1, E2, and E3 activities - is no longer available (Fig. $8 \mathrm{~B}$ ). Following either proteasomal or E1 inhibition, we did not observe a general increase in the levels of ubiquitinated proteins within the time frame (minutes) of the observed mini frequency rise (Fig. $8 \mathrm{~A}$ ). We also did not find an increase in either Munc-13 (Aravamudan and Broadie, 2003; Speese et al., 2003) (but see Kalla et al., 2006) or Rim1 (Yao et al., 2007) levels (Figs. 4B, C, 5C,D). Obviously, we cannot exclude changes of protein levels that are below our detection limits. Indeed, in response to proteasome inhibition at least a small increase in global ubiquitination levels might be expected even after short exposure and such an increase has been reported by others (Patrick et al., 2003). In response to E1 inhibition on the other hand, a decrease in global ubiquitination would be expected even shortly after inhibition. Thus an opposite change of ubiquitination might be expected in response to inhibition at these two checkpoints. Since all four inhibitors working at these distinct checkpoints of the UPS have the same physiological effect, a decrease in the ubiquitination level of dynamically ubiquitinated proteins is most consistent with the observed increase in quantal release.

The rapid increase in mini frequency with no consistent alteration of mini amplitude in response to proteasome and E1 inhibition suggests a predominantly presynaptic site of action. This could be due to an increase in the size of the readily releasable pool of vesicles, an increase in release probability, an awakening of presynaptically silent (mute) synapses, or a combination of these. However, we do not want to exclude contributions of unsilencing of postsynaptically silent (deaf) synapses, or a scheme of postsynaptic induction followed by presynaptic expression, as underlying or at least contributing mechanisms. Given the many synaptic proteins that have been reported as targets of ubiquitination (Hegde and DiAntonio, 2002) and given the large number and potential specificity of E3-ligases, the molecular pathways contributing to a UPS-mediated regulation of synaptic transmission will likely prove to be very diverse.

In conclusion, our results add a novel layer to the growing appreciation of the regulatory effect of the UPS on synaptic transmission. Inhibition of the UPS over many hours to days appears to contribute to neuronal dysfunction and death in neurodegenerative diseases (Hegde and Upadhya, 2007). Inhibition over tens of minutes to hours has been shown to affect the size of the recycling pool of vesicles (Willeumier et al., 2006), postsynaptic receptor trafficking (Patrick et al., 2003), the strength of synaptic transmission (Speese et al., 2003; Zhao et al., 2003), and LTP (Dong et al., 2008). We now show that neurotransmitter release is controlled by the UPS on a timescale of minutes or less. These fast effects might in part provide the physiological basis for functions on a longer time scale. The consistent dysregulation of synaptic transmission in response to UPS malfunction might underlie early aspects of neurodegenerative diseases. This notion is supported by the accumulating evidence that pesticides inhibit UPS function (Wang et al., 2006) and that individuals living close to agricultural areas exposed to pesticides have an increased risk of developing Parkinson's disease (Ritz and Costello, 2006; Costello et al., 2009). Thus, it will be interesting to investigate whether malfunctioning of the rapid regulation of synaptic transmission by the ubiquitin-proteasome system-in addition to pointing toward a novel mechanism of synaptic regulation and plasticity-could serve as an early indicator of long-term neuronal dysfunction.

\section{References}

Aravamudan B, Broadie K (2003) Synaptic Drosophila UNC-13 is regulated by antagonistic G-protein pathways via a proteasome-dependent degradation mechanism. J Neurobiol 54:417-438.

Bingol B, Schuman EM (2004) A proteasome-sensitive connection between PSD-95 and GluR1 endocytosis. Neuropharmacology 47:755-763.

Chou AP, Maidment N, Klintenberg R, Casida JE, Li S, Fitzmaurice AG, Fernagut PO, Mortazavi F, Chesselet MF, Bronstein JM (2008) Ziram causes dopaminergic cell damage by inhibiting E1 ligase of the proteasome. J Biol Chem 283:34696-34703.

Ciechanover A, Schwartz AL (2004) The ubiquitin system: pathogenesis of human diseases and drug targeting. Biochim Biophys Acta 1695:3-17.

Conaway RC, Brower CS, Conaway JW (2002) Emerging roles of ubiquitin in transcription regulation. Science 296:1254-1258.

Costello S, Cockburn M, Bronstein J, Zhang X, Ritz B (2009) Parkinson's disease and residential exposure to maneb and paraquat from agricultural applications in the central valley of California. Am J Epidemiol 169:919-926.

DiAntonio A, Haghighi AP, Portman SL, Lee JD, Amaranto AM, Goodman CS (2001) Ubiquitination-dependent mechanisms regulate synaptic growth and function. Nature 412:449-452.

Dong C, Upadhya SC, Ding L, Smith TK, Hegde AN (2008) Proteasome 
inhibition enhances the induction and impairs the maintenance of latephase long-term potentiation. Learn Mem 15:335-347.

Efron B, Tibshirani R (1991) Statistical data analysis in the computer age. Science 253:390-395.

Ehlers MD (2003) Activity level controls postsynaptic composition and signaling via the ubiquitin-proteasome system. Nat Neurosci 6:231-242.

Fang S, Weissman AM (2004) A field guide to ubiquitylation. Cell Mol Life Sci 61:1546-1561.

Fonseca R, Vabulas RM, Hartl FU, Bonhoeffer T, Nägerl UV (2006) A balance of protein synthesis and proteasome-dependent degradation determines the maintenance of LTP. Neuron 52:239-245.

Fulga TA, Van Vactor D (2008) Synapses and growth cones on two sides of a highwire. Neuron 57:339-344.

Haas KF, Broadie K (2008) Roles of ubiquitination at the synapse. Biochimica et Biophysica Acta 1779:495-506.

Hegde AN, DiAntonio A (2002) Ubiquitin and the synapse. Nat Rev Neurosci 3:854-861.

Hegde AN, Upadhya SC (2007) The ubiquitin-proteasome pathway in health and disease of the nervous system. Trends Neurosci 30:587-595.

Hicke L (2001) A new ticket for entry into budding vesicles-ubiquitin. Cell 106:527-530.

Jha N, Kumar MJ, Boonplueang R, Andersen JK (2002) Glutathione decreases in dopaminergic PC12 cells interfere with the ubiquitin protein degradation pathway: relevance for Parkinson's disease? J Neurochem 80:555-561.

Kaiser P, Fon EA (2007) Expanding horizons at Big Sky. Symposium on ubiquitin and signaling. EMBO Rep 8:817-822.

Kalla S, Stern M, Basu J, Varoqueaux F, Reim K, Rosenmund C, Ziv NE, Brose N (2006) Molecular dynamics of a presynaptic active zone protein studied in Munc13-1-enhanced yellow fluorescent protein knock-in mutant mice. J Neurosci 26:13054-13066.

Karpova A, Mikhaylova M, Thomas U, Knöpfel T, Behnisch T (2006) Involvement of protein synthesis and degradation in long-term potentiation of Schaffer collateral CA1 synapses. J Neurosci 26:4949-4955.

Kisselev AF, Goldberg AL (2005) Monitoring activity and inhibition of $26 \mathrm{~S}$ proteasomes with fluorogenic peptide substrates. Methods Enzymol 398:364-378.

Kiyonaka S, Wakamori M, Miki T, Uriu Y, Nonaka M, Bito H, Beedle AM, Mori E, Hara Y, De Waard M, Kanagawa M, Itakura M, Takahashi M, Campbell KP, Mori Y (2007) RIM1 confers sustained activity and neurotransmitter vesicle anchoring to presynaptic $\mathrm{Ca} 2+$ channels. Nat Neurosci 10:691-701.

Lewcock JW, Genoud N, Lettieri K, Pfaff SL (2007) The ubiquitin ligase Phr1 regulates axon outgrowth through modulation of microtubule dynamics. Neuron 56:604-620.

Li YX, Zhang Y, Lester HA, Schuman EM, Davidson N (1998) Enhancement of neurotransmitter release induced by brain-derived neurotrophic factor in cultured hippocampal neurons. J Neurosci 18:10231-10240.

Lou X, Scheuss V, Schneggenburger R (2005) Allosteric modulation of the presynaptic Ca2 + sensor for vesicle fusion. Nature 435:497-501.

Mailhes JB, Hilliard C, Lowery M, London SN (2002) MG-132, an inhibitor of proteasomes and calpains, induced inhibition of oocyte maturation and aneuploidy in mouse oocytes. Cell Chromosome 1:2.
Manning G, Whyte DB, Martinez R, Hunter T, Sudarsanam S (2002) The protein kinase complement of the human genome. Science 298:19121934.

Mukhopadhyay D, Riezman H (2007) Proteasome-independent functions of ubiquitin in endocytosis and signaling. Science 315:201-205.

Patrick GN, Bingol B, Weld HA, Schuman EM (2003) Ubiquitin-mediated proteasome activity is required for agonist-induced endocytosis of GluRs. Curr Biol 13:2073-2081.

Ritz B, Costello S (2006) Geographic model and biomarker-derived measures of pesticide exposure and Parkinson's disease. Ann N Y Acad Sci 1076:378-387.

Schoch S, Castillo PE, Jo T, Mukherjee K, Geppert M, Wang Y, Schmitz F, Malenka RC, Südhof TC (2002) RIM1alpha forms a protein scaffold for regulating neurotransmitter release at the active zone. Nature 415:321326.

Shimura H, Hattori N, Kubo S, Mizuno Y, Asakawa S, Minoshima S, Shimizu N, Iwai K, Chiba T, Tanaka K, Suzuki T (2000) Familial Parkinson disease gene product, parkin, is a ubiquitin-protein ligase. Nat Genet 25:302-305.

Sippy T, Cruz-Martín A, Jeromin A, Schweizer FE (2003) Acute changes in short-term plasticity at synapses with elevated levels of neuronal calcium sensor-1. Nat Neurosci 6:1031-1038.

Speese SD, Trotta N, Rodesch CK, Aravamudan B, Broadie K (2003) The ubiquitin proteasome system acutely regulates presynaptic protein turnover and synaptic efficacy. Curr Biol 13:899-910.

Sutovsky P, McCauley TC, Sutovsky M, Day BN (2003) Early degradation of paternal mitochondria in domestic pig (Sus scrofa) is prevented by selective proteasomal inhibitors lactacystin and MG132. Biol Reprod 68:17931800 .

Wang XF, Li S, Chou AP, Bronstein JM (2006) Inhibitory effects of pesticides on proteasome activity: implication in Parkinson's disease. Neurobiol Dis 23:198-205.

Willeumier K, Pulst SM, Schweizer FE (2006) Proteasome inhibition triggers activity-dependent increase in the size of the recycling vesicle pool in cultured hippocampal neurons. J Neurosci 26:11333-11341.

Wilson SM, Bhattacharyya B, Rachel RA, Coppola V, Tessarollo L, Householder DB, Fletcher CF, Miller RJ, Copeland NG, Jenkins NA (2002) Synaptic defects in ataxia mice result from a mutation in Usp14, encoding a ubiquitin-specific protease. Nat Genet 32:420-425.

Yang Y, Kitagaki J, Dai RM, Tsai YC, Lorick KL, Ludwig RL, Pierre SA, Jensen JP, Davydov IV, Oberoi P, Li CC, Kenten JH, Beutler JA, Vousden KH, Weissman AM (2007) Inhibitors of ubiquitin-activating enzyme (E1), a new class of potential cancer therapeutics. Cancer Res 67:9472-9481.

Yao I, Takagi H, Ageta H, Kahyo T, Sato S, Hatanaka K, Fukuda Y, Chiba T, Morone N, Yuasa S, Inokuchi K, Ohtsuka T, Macgregor GR, Tanaka K, Setou M (2007) SCRAPPER-dependent ubiquitination of active zone protein RIM1 regulates synaptic vesicle release. Cell 130:943-957.

Yi JJ, Ehlers MD (2007) Emerging roles for ubiquitin and protein degradation in neuronal function. Pharmacol Rev 59:14-39.

Zhao Y, Hegde AN, Martin KC (2003) The ubiquitin proteasome system functions as an inhibitory constraint on synaptic strengthening. Curr Biol 13:887-898. 